\title{
Potential Study Subject
}

National Cancer Institute

\section{Source}

National Cancer Institute. Potential Study Subject. NCI Thesaurus. Code C70678.

A living individual who, due to the possession of one or more characteristics such e.g. as a particular medical condition specific to the study, is pre-qualified as a prospective study subject. A potential subject becomes eligible for the clinical study if he meets the study protocol eligibility criteria and voluntarily gives a leg ally effective informed consent to participate in the study (except when a waiver for informed consent is granted under FDA and OHRP guidelines). 